\title{
The Time is Now: A 10-Year Vision and Strategy to Advance the Life Sciences
}

\author{
Barbara Atkinson, MD \\ Executive Vice Chancellor, University of Kansas Medical Center \\ Executive Dean, University of Kansas School of Medicine
}

$\mathrm{T}$ he University of Kansas Medical Center has embarked on a 10-year journey to become a world-class life sciences research and teaching institution. Our goal is to effectively enhance and link basic and clinical research, and to provide the leadership to translate those achievements into improved health care and quality of life for the greater Kansas City region, the State of Kansas, and the nation. This journey represents the vision of not one organization, but many.

The University of Kansas Medical Center's (KUMC) 10-year life sciences strategy is based on a regional collaboration among the region's many life sciences assets, including the Stowers Institute for Medical Research, Midwest Research Institute, University of Missouri-Kansas City, University of Kansas-Lawrence, Kansas City University of Medicine and Biosciences, the Veterans Administration Hospitals, University of Kansas Hospital, Saint Luke's Health System, Children's Mercy Hospitals and Clinics, and Truman Medical Center. This long-term strategy is further bolstered by the area's focus on entrepreneurial and collaborative life sciences research activities supported by the Kansas City Area Life Sciences Institute, the Kansas Bioscience Authority, the area's clinical research organizations, and the strong regional philanthropic base.
Regional collaboration is paramount to reaching KUMC's vision of attaining world-class status and the greater Kansas City area's goal of becoming a top-20 life sciences region within 10 years. Other markets, such as Boston, Philadelphia, and San Diego, which are world-renowned for their achievement in the life sciences, have strong partnerships among their academic medical centers, public and private universities, multiple area hospitals, and private research institutions.

Similar collaborative strategies are being implemented in markets like Cleveland, Indianapolis, Los Angeles, and Phoenix, where the focus on a common research university is creating new opportunities for numerous institutions. Each of these markets share academic medical centers that stand out as the centerpiece of their respective life sciences communities. They provide synergies between public and private 
institutions, elevating life sciences research and entrepreneurialism.

As articulated by the Greater Kansas City Community Foundation's Time to Get it Right report ${ }^{1}$, a successful life sciences strategy for the greater Kansas City region must include significant investments in its academic institutions. For KUMC, the report identified many opportunities for achieving world-class status, making it clear that KUMC must be at the forefront to promote a united regional vision that transcends the state line to bring area assets together for a common purpose.

Although this document is a road map to expand the research capabilities of the University and its Medical Center, it in no way diminishes our commitment to educating and training physicians and health care professionals for Kansas and the region. We remain steadfast in our education mission and recognize that quality researchers and clinicians often make the best teachers for our students. It is also important to note that this document is focused on research activities primarily housed on the Lawrence and Kansas City campuses. We recognize the stellar work that is conducted at the School of MedicineWichita campus and look forward to working with our colleagues and stakeholders in Wichita to outline their vision for the future.

\section{The Transformation}

The 10-year journey requires transformation at many levels.

KUMC's partnerships with life sciences organizations must be expanded and enhanced to support the region's and the University's long-term life sciences strategies. In addition, a similar transformation must occur within KUMC and across the related disciplines in the University of Kansas system. That internal transformation must fully integrate the Medical Center's biomedical research departments with complementary programs and efforts at the University of Kansas-Lawrence and the KU School of Medicine-Wichita. Doing so successfully will require a focus on three important areas: translational research, drug discovery, and the cultivation of research talent.

\section{Translational Research}

A key component to this transformation will be a renewed focus on advancing the translational research capabilities of KUMC across many disciplines. We will work to streamline the process of moving discoveries from the bench to the bedside, and we'll dedicate new resources to these efforts.

This focus on translational research is consistent with the National Institutes of Health's (NIH) recent launch of its Roadmap for Medical Research and, in particular, its priority for Re-engineering the Clinical Research Enterprise. The NIH Roadmap calls for a new emphasis on translational research designed to improve the movement of new discoveries from the bench to the bedside. Achieving excellence in translational research and drug discovery and development will allow KUMC and KU faculty to make more significant progress in disease prevention methods, diagnostics, and lifesaving treatments for patients. 
The foundation for excellence in translational research already exists within KUMC. In October 2006, the NIH awarded KUMC, the Kansas City University of Medicine and Biosciences, and the Kansas City Veterans Administration Hospital - collaborators in the new Heartland Institute for Clinical and Translational Research (HICTR) - one of the new Clinical and Translational Science Award planning grants. Selection for this competitive award is a solid indicator that KUMC has what it takes to become a national leader in translational research.

In addition, there is more good news. KUMC just received another NIH grant totaling $\$ 7$ million to support translational and clinical research in the Kansas City area. Together, these two grants position the HICTR to facilitate the translation of lab discoveries into lifesaving cures and to become a national model for excellence.

\section{Drug Discovery}

Connected with the HICTR is the drug discovery initiative at both the Kansas City and Lawrence campuses. A bi-campus team has come together to effectively articulate a 10-year drug discovery strategic plan focused on establishing the University of Kansas and its Medical Center as a premier institution in pharmaceutical research, pharmaceutical education, and commercialization of resulting intellectual property. A key player in this process is the Office of Therapeutics, Discovery and Development (OTDD), which was developed and launched in January 2006 as a bi-campus initiative to streamline and improve the drug discovery and development process. While the OTDD's first focus area is cancer, the university expects there will be many opportunities for other disease areas to benefit from the process developed for cancer.

\section{Cultivating Researcher Talent}

The 10-year life sciences vision demands that KU and its Medical Center not only break new ground in the translation of research, but also provide a thriving research enterprise and the growing cadre of leaders to support this growth. In keeping with the educational mission of an academic medical center and the recommendations of the Blue Ribbon Task Force, it will be important to expand the $\mathrm{PhD}$ program offerings and add post-doctoral personnel for specific research projects. PhD students and post-doctoral personnel are essential contributors to any research environment. Increased emphasis on attracting talented students and postdocs to both the Kansas City and Lawrence campuses will be critical.

\section{Needed Investment}

The transformation of KUMC will require significant growth - and to that end, significant philanthropic and private investment. Over the next 10 years, KUMC will require an ongoing investment from the community to recruit 152 senior and 92 junior faculty and build and outfit more than 862,500 square feet of new research space.

With the addition of 244 faculty as part of the 10-year plan, KUMC has set a goal of increasing extramural grant funding (National Institutes of Health and other external sources) from approximately $\$ 85$ million per year to 
$\$ 170$ million per year by year five and $\$ 340$ million per year by year 10 .

The 10-year costs for faculty and facilities are estimated at $\$ 798.6$ million.

\section{Anticipated Return on Investment}

While \$798.6 million may seem extravagant to recruit new faculty researchers and build and outfit state-ofthe-art facilities for their work, all economic indicators point to the potential for this investment to reap economic impact in the billions of dollars for years to come.

The amount of investment required is comparable to that of anew theme park or redevelopment of an entertainment district. The difference? In addition to fueling economic development, we will save lives.

Over the last five years, a number of studies have been conducted as part of the greater Kansas City life sciences initiative and the Kansas Economic Growth Act to indicate the potential return on research investments. The following highlights provide some illustration of the potential economic benefit of a substantial investment in the life sciences programs at KUMC and KU.

An economic impact analysis for Phase II of the Stowers Institute for Medical Research conducted by Andersen Consulting (2002) ${ }^{2}$ projected that adding one million square feet of research space and 900 researchers would mean more than $\$ 1.4$ billion to the regional economy over 10 years.

The Kansas Economic Growth Act's Bioscience Initiative (2004) ${ }^{3}$ was the first in Kansas to demonstrate that investing in the life sciences could mean significant growth in jobs and research funding across the state. A study conducted by the Kansas Technology Enterprise Corporation and Ernst \& Young LLP projected that a $\$ 500$ million state investment over approximately 10 years in life sciences researchers, facilities, technology transfer, and commercialization would yield 23,000 new bioscience jobs, 20,000 indirect jobs, more than $\$ 1$ billion in research funding, and more than 100 new start-up companies.

The Perryman Group Study (2005) ${ }^{4}$, supported by the Kansas Technology Enterprise Corporation on behalf of the University of Kansas Cancer Center, demonstrates similar and even more farreaching economic impacts associated with investment in the life sciences over 10 years. The Perryman Group specifically evaluated the impact of building a National Cancer Institutedesignated Comprehensive Cancer Center at the University of Kansas. Based on extensive economic modeling, the study's authors projected a $\$ 1.3$ billion economic impact in year 10 and every year thereafter, which includes $\$ 80$ million in extramural research funding, 9,400 permanent direct and indirect jobs, and $\$ 584$ million in related social gains due to reduced cancer mortality.

The investments required to pursue this vision are significant, but they promise returns of economic, health, and social gains that stand to transform our entire region.

\section{KUMC Life Science Programs}

Within the 10-year KU/KUMC life sciences strategy are a number of established and emerging disease and 
organ-based research programs, translational research programs, and shared resources that need additional investment to support the broader initiative. Each program requires the recruitment of senior and junior faculty as well as space to conduct research and access to shared resources.

\section{Established Programs}

The established disease and organbased research programs currently enjoy strong extramural grant funding and a critical mass of faculty supporting the research and, in many cases, clinical goals. They are the most developed of KUMC programs and, in numerous instances, are already demonstrating significant leadership on a national scale in the form of research publications, clinical care, and patent filings. Key faculty appointments and additional consolidated research space will lead to further enhancement of these programs. The six established disease and organbased programs are:

- Cancer

- Neuroscience/Brain Health

- Maternal/Fetal/Child Health

- Reproductive Sciences/Fertility

- Kidney

- $\quad$ Liver

\section{Emerging Programs}

The emerging disease and organbased research programs are in development and have an initial core of faculty and research grants that warrant additional emphasis and funding. Along with the established programs, many of the emerging programs will play a significant role in the development of the Heartland Institute for Clinical and Translational Research and will benefit from the efforts to streamline the drug discovery and development process. These programs include:

- Bioengineering

- Bone

- Diabetes

- Heart

- Immunology/Virology

- Integrative Medicine

- Obesity

- Ophthalmology

- Personalized Medicine

- Public Health

\section{Translational Research Programs}

The translational research programs are interdisciplinary in nature and typically involve a number of disease and organ-based research programs as well as shared resources. The focus of these programs is to improve the translation of basic research into lifesaving cures for patients. KUMC's translational research programs have the potential to differentiate our community's broader life sciences strategy from the rest of the country. Two programs critical to achieving this potential are:

- Heartland Institute for Clinical and Translational Research (HICTR)

- Drug Discovery

\section{Shared Resources}

Shared resources are functions or services within the university that support a number of disease and organbased research programs and are critical to processing and analyzing data, running tests, and conducting research. Growth in the disease and organ-based research programs cannot occur without 
parallel investments in shared resources. These shared resources are:

- Bioinformatics

- Biostatistics

- Compound Synthesis

- High Throughput Screening

- Mass Spectrometry/Proteomics

\section{Conclusion}

The Greater Kansas City Community Foundation's Time to Get it Right report could not have said it better - it truly is the time to get it right.

The time has come to commit to a focused long-term strategy that will transform the University of Kansas Medical Center into a high-performing institution driving new knowledge and lifesaving cures - one that will play an integral role in the cultivation of our regional life sciences opportunities. The benefits are clear - the greater Kansas City region and the State of Kansas will be players in the new, knowledge-based, global economy. And more importantly, we will improve the health of our citizens and prosper as a community.

The more than $\$ 2$ billion investment in the Stowers Institute for Medical Research, the 10-year, \$500 million investment in the biosciences by the State of Kansas, and the work to unite investment in the life sciences community, led by the Kansas City Area Life Sciences Institute, the Greater Kansas City Community Foundation and others, have created momentum towards excellence.

The foundation for KUMC's 10-year life sciences strategy has been in the works for many years, and progress to date has been considerable. The time is ripe to capitalize on this region's momentum and to reach for the next level - a level worthy of worldwide recognition.

Our goals are ambitious, and they will require the unified creativity and commitment of the entire region. Together we can recruit top talent, build and renovate world-class research laboratories, and attract external funding. We are poised to become a leading center of excellence in the life sciences.

The time is right...the time is now.

A 10-year, \$798.6 million investment supporting established, emerging, and translational research programs and shared resources at KU and KUMC will bring to our region new jobs, new scholars, and new discoveries. It will foster economic development while improving our ability to train health care professionals, and it will give those professionals better options for treating devastating diseases. The transformation is within our reach.

Our dream has a plan...help us make it a reality.

\section{References}

1. Greater Kansas City Community Foundation, Time to Get it Right report http://www.gkccf.org/page228S4.cfm

2. Anderson Consulting, 2002. Economic Impact Analysis for Stowers Research Institute Phase II.

3. The Kansas Economic Growth Act: Economic Growth through Discovery, Innovation \& Entrepreneurship. January 2004; Ernst \& Young LLP, Kansas Biosciences: Potential Contributions to State and Local Tax Revenues, 2004-2013, January 2004.

4. The Perryman Group, 2005. The Potential Impact of an Enhanced Emphasis on Cancer Research at the University of Kansas Medical Center on Business Activity in Kansas and the Kansas City Metropolitan Area. Report prepared for the Kansas Technology Enterprise Corporation. 